$\mathrm{CO}_{2}$ due to fossil-fuel consumption can be significantly reduced via the adoption of realistic energy strategies that are relatively " $\mathrm{CO}_{2}$-benign"-[by which] we mean an atmospheric $\mathrm{CO}_{2}$ increase from its present 340 parts per million volume to about 420 parts per million by the year 2050 , corresponding to a " $\mathrm{CO}_{2}$-doubling time" of several centuries.'

The MIT and Stanford specialists urge early action because it will minimize later difficulties. They noted that 'the time from conception of a new energy-supply technology to its widespread adoption is half a century or longer.' Although they urge an international approach to the problem, the three specialists acknowledge that it will be impossible to develop a global consensus for any one simple set of energy options-because of different stages of industrialization, different available resources, different perceptions of climatological or economic winning or losing, and other factors. However, 'the time seems propitious to extend the global debate on $\mathrm{CO}_{2}-$ climate, based on recent attention to other international environmental problems, [and] to the benefit of all.'

The report calls for the close study of electric power. 'The trend toward a more-electric future world, coupled with the fact that most non-fossil energy options are electric, indicates the need for and benefit of studying future electric systems closely. Electric power systems that incorporate storage, interactive load-control, and other operations involving joint generator-user decisions and technologies, will make electric power-systems much more versatile and responsive to demand, and result in cheaper average costs of electric power' than curently obtain.

The report also cites the need for more work in developing long-term energy-carbon dioxide models, 'particularly on how to account for the possibility of $\mathrm{CO}_{2}$ climate changes on the energy-economic system.' In it are evaluated several energy-sources. Thus increased use of coal, the report says, would not be limited by availability or by extraction cost, but would be affected by 'a continuing shift toward a more technologically sophisticated world, for which electricity is better matched than heat by flames - a shift that reduces demand for all combustible fuel, not just coal.'

Nuclear fission, the report says, costs significantly less than coal power in many places in the world, 'especially given environmental restrictions against coal [that are] typical of present US practices.' Nuclear power will be cheaper almost everywhere that environmental restrictions on coal are significantly increased. Although nuclear fission is currently at an impasse in the United States, it is being pursued vigorously in other industrialized countries. Its long-term future depends on such factors as technological advances, improvements in the management of the nuclear enterprise, and how fission compares with other options on economic and environmental grounds. On the other hand, nuclear fusion 'will not be ready for significant commercial power-production during the critical period before 2050 ,' the report says.

Because of possible high environmental costs and limits on the amount available, biomass may be used only for premium needs or by people living near exploitable forests 'who are not part of a money economy.' However, the possibility exists for arrays of photovoltaic cells to become a major energy-source for many countries. During the past ten years, improvements in manufacturing techniques and increased volume of production have led to significant cost reductions in this connection. However, substantial deployment will probably not occur before the year 2000 , both because of the need to reduce present costs still further and also due to problems associated with its intermittent nature and high materialand land-use. Yet the report says that these difficulties can probably be resolved by more versatile electric powersystems and by judicious use of land which is relatively unproductive for other purposes.

Efforts to reduce energy consumption could occur without adversely affecting the gross national product, the report says. Energy per unit of GNP in constant dollars, or per unit of physical output, could decrease at the rate of about $1 \%$ per year without economic harm, because of long-term technological improvement and system replacement. 'This improvement seems achievable in all regions and sectors,' the report says, concluding that 'this is the most important single opportunity to ameliorate $\mathrm{CO}_{2}$ buildup and appears attractive in its own right, both economically and environmentally.'

RALPH KAZARIAN
National Science Foundation
1800 G Street
Washington
DC 20550
USA.

\title{
How Hong Kong Could Solve an Animal Waste Pollution Problem
}

A plan to prevent the dumping of farm manure, which is generated locally at the rate of $c a 2,000$ tonnes a day, has been submitted to the Hong Kong Government by ERL (ASIA) Ltd, in association with HFA Hong Kong and Watson Hawksley Asia, as part of the campaign to end agricultural pollution in the New Territories. Most of the excreta produced by the Territory's vast population of pigs and chickens is currently discharged untreated into streams (Fig. 1) which are used for irrigation and flow into pools that are also used for fishing and bathing. Furthermore, these watercourses are subject to overflow, thus creating an environmental hazard over considerable areas.

The problem has been investigated for the Environmental Protection Agency of the Hong Kong Government by the above-mentioned consultant firms. Lead consultant was ERL (ASIA) Ltd, the Hong Kong-based subsidiary of Environmental Resources Limited, which has its headquarters in London and acts as specialist consultant for governments and major companies in many parts of the world.

A combination of treatment methods has been recommended dry handling of wastes on small farms and wet handling on large farms, combined with properly managed disposal. A variable amount of liquid/solids separation can be carried out on-site, depending on the size of the farm and the local circumstances. Although several recycling possibilities were explored, ranging from soil conditioning to methane production, the consultants found that these could not provide a general solution. Too often, no developed market existed for the product, although it was established that prevailing trade with southern China in some animal wastes could be further developed, while a limited market existed within Hong Kong for composted products (Fig. 2). The consultants also recommended establishing sites for relocating 


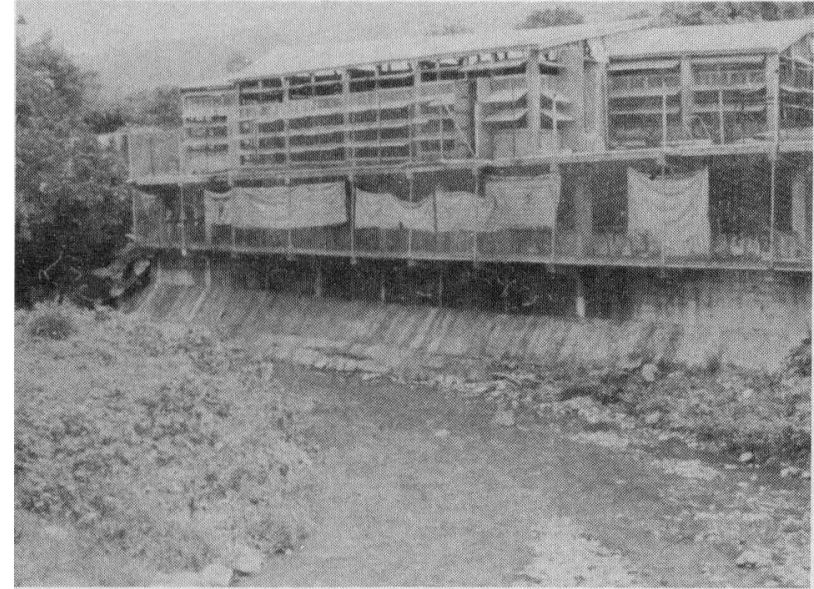

Fig. 1. Streamside farm in Hong Kong's New Territories, with excreta and other effluent still being discharged untreated into the stream.

farmers who, for reasons of space or accessibility, could not comply with the controls.

Under the proposed scheme, a nine-years' programme costing some HK $\$ 265$ millions (about $£ 24$ millions) would provide for the treatment of animal wastes collected from farms, the resulting sludge being disposed of with municipal waste at landfall sites. Farmers would be unable to bear the full cost of the programme, the

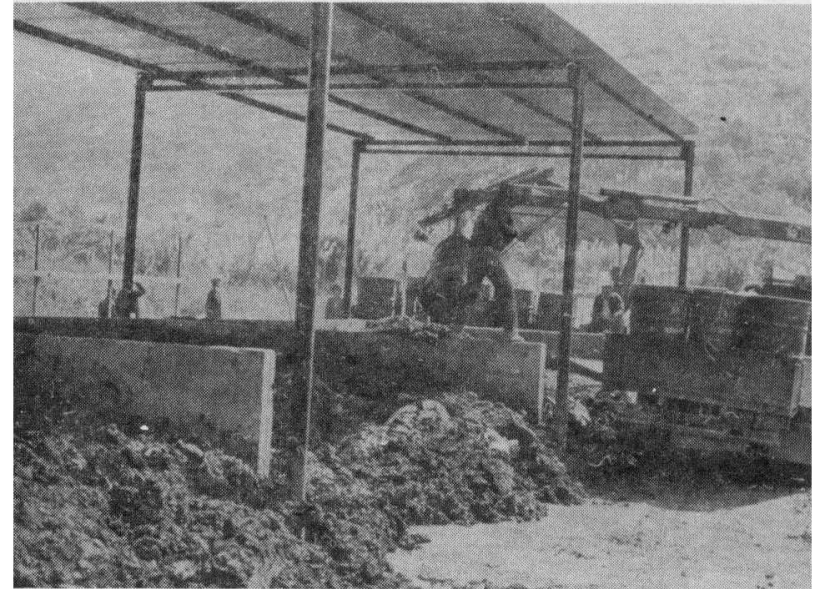

Fig. 2. Composting plant at Ngau Tam Mei, Hong Kong.

consultants have advised, and some financial support, possibly from a special levy, would be essential.

\author{
ROBERT BIDWELL, Director \\ Environmental Resources Limited \\ 79 Baker Street \\ London WIM IAJ \\ England, UK.
}

\section{Leprosy, Continuing Factor of the Human Environment}

Leprosy still occurs in more than 70 countries, mainly in Africa and Asia, but also in some South and Central American countries. It is caused by Micobacterium leprae, first described by Gerhard Armaner Hansen of Norway in 1873, and has a long incubation period-generally from three to 10 years. According to WHO estimates, there are between 10 and 11 million leprosy cases in the world, about half of whom have been identified by the health services.

In countries where leprosy occurs, the number of cases does not usually exceed $5 \%$ of the total population. Nevertheless, some four million people are disabled to various degrees as a result of this disease. Their disfigurement causes aversion, resulting in serious psychological and social problems for the leprosy patients and their families.

Many leprosy cases have a benign form and tend to heal spontaneously. But a considerable number of cases, called lepromatous, harbour large numbers of the bacilli and are seriously affected; these cases show a gradual progression of the disease when untreated. They also constitute the principal source of transmission.

The mechanism of transmission of the leprosy Bacterium and the factors which determine the occurrence of the disease in persons infected with it are still unclear. Leprosy is not a hereditary disease, but constitutes a far more serious problem than the sheer number of cases belies, as it involves disabilities, economic loss, and psychological trauma for those affected. Leprosy is, in general, associated with poverty.

Formerly, the basis of leprosy control consisted of the administration of one drug, called Dapsone, which had to be given for many years. Unfortunately in recent years, resistance to Dapsone has become a major problem, and today, WHO recommends the use of combinations of drugs as the basis of therapy. These combinations are more expensive, more complex to administer, and require greater supervision, than did Dapsone. However, the fact that they are far more efficient means that they do not have to be used over such long periods of time, as was the case with Dapsone alone-thus making them more economical in the long run.

All countries where leprosy occurs are now making efforts to introduce this new therapy into their leprosy control programmes. In the past, as a result of prejudice against leprosy, many leprosy control programmes were conducted in a specialized manner. Since the leprosy control strategy is based on early diagnosis and regular treatment, the corresponding activities require full community participation and therefore are to be included first and foremost in the primary health-care (PHC) system.

WHO plays a world-wide role in coordinating, supporting, and stimulating, effective leprosy control programmes within the primary health-care approach. The strategy of control is based on early case-detection and regularly supervised multidrug therapy. All countries where leprosy occurs receive assistance for their leprosy control programmes from many bilateral and voluntary agencies.

An international research network into the Immunology of Leprosy (IMMLEP) and the Chemotherapy of Leprosy (THELEP) has been set up under the United Nations Development Programme/World Bank/WHO Special Programme for Research and Training in Tropical Diseases. The multidrug regimens are an important outcome of this research. The progress in research aimed at producing a leprosy vaccine is also encouraging.

Division of Public Information World Health Organization 1211 Geneva 27 Switzerland. 